\title{
Long-term changes in Symbiodinium communities in Orbicella annularis in St. John, US Virgin Islands
}

\author{
Peter J. Edmunds ${ }^{1, *}$, Xavier Pochon ${ }^{2,3}$, Don R. Levitan ${ }^{4}$, Denise M. Yost ${ }^{2}$, \\ Mahdi Belcaid ${ }^{2}$, Hollie M. Putnam ${ }^{2}$, Ruth D. Gates ${ }^{2}$ \\ ${ }^{1}$ Department of Biology, California State University, 18111 Nordhoff Street, Northridge, CA 91330-8303, USA \\ ${ }^{2}$ Hawaii Institute of Marine Biology, University of Hawaii, PO Box 1346, Kaneohe, HI 96744, USA \\ ${ }^{3}$ Environmental Technologies, Cawthron Institute, 98 Halifax Street East, Private Bag 2, Nelson 7042, New Zealand \\ ${ }^{4}$ Department of Biological Science, Florida State University, Tallahassee, FL 32306-4295, USA
}

\begin{abstract}
Efforts to monitor coral reefs rarely combine ecological and genetic tools to provide insight into the processes driving patterns of change. We focused on a coral reef at $14 \mathrm{~m}$ depth in St. John, US Virgin Islands, and used both sets of tools to examine 12 colonies of Orbicella (formerly Montastraea) annularis in 2 photoquadrats that were monitored for $16 \mathrm{yr}$ and sampled genetically at the start and end of the study. Coral cover and colony growth were assessed annually, microsatellites were used to genetically identify coral hosts in 2010, and their Symbiodinium were genotyped using chloroplastic 23S (cloning) and nuclear ITS2 (cloning and pyrosequencing) in 1994 and 2010. Coral cover declined from 40 to $28 \%$ between 1994 and 2010, and 3 of the 12 sampled colonies increased in size, while 9 decreased in size. The relative abundance of Symbiodinium clades varied among corals over time, and patterns of change differed between photoquadrats but not among host genotypes. Symbiodinium communities in 8 corals in 1 photoquadrat differed among colonies and changed over time, with a trend towards reduced abundance of clade C and increased abundance of clade B. Symbiodinium communities in 4 corals in the second photoquadrat were similar among colonies, dominated by clade $C$, and remained relatively constant in clade composition over time. Based on an analysis that sampled only a small number of corals, but is unique in the long temporal scale and the combination of techniques employed, this study demonstrates that the processes underlying shifts in coral cover are complex and difficult to predict. Meter-scale variation in reef microhabitats affected Symbiodinium communities in $O$. annularis, and host genotype coupled with variation in Symbiodinium communities appeared to mediate colony success.
\end{abstract}

KEY WORDS: Orbicella $\cdot$ Montastraea $\cdot$ Symbiodinium · Genetics · Ecology · Long-term · Virgin Islands Resale or republication not permitted without written consent of the publisher

\section{INTRODUCTION}

Long-term ecological analysis is the most effective way to detect temporal changes in community structure, and, while the most basic tool of this trade is natural history, most contemporary efforts are quantitative (Hairston et al. 2005). Studies vary from single-investigator projects to grand initiatives, such as the United States Long-Term Ecological Research network (Gosz et al. 2010), and the temporal scale can extend over decades or centuries (or longer) depending on the length of the study and the potential to exploit legacy data or the fossil record (Jablonski \& Sepkoski 1996). Despite advances in understanding of community dynamics that have come from time-series analyses, most studies continue to rely heavily on measurements of organism abundance and size, which are of limited value in elucidating processes that drive patterns of change (Lindenmayer \& Likens 2010). 
Coral reefs were once best known for their beauty and biological diversity, but over the last $20 \mathrm{yr}$ they have become the poster child for ecosystem degradation. This change in perception reflects the widespread death of corals through disturbances of natural and anthropogenic origin (Hoegh-Guldberg et al. 2007). When the impacts of disturbances on coral reefs were publicized in the 1980s (e.g. Woodley et al. 1981), their effects at the time were contextualized by only a handful of studies documenting the dynamics of coral communities in undisturbed conditions (e.g. Goreau 1959, Loya 1972). Much has changed since these early analyses, including a proliferation of descriptions of the stressors threatening coral reefs (Hoegh-Guldberg et al. 2007), breakthroughs in understanding the functional biology of corals (Baird et al. 2009), and the implementation of largescale efforts to record the changes underway (e.g. De'ath et al. 2012). It is still rare, however, to find studies that use traditional ecological tools in combination with molecular tools such as those used to identify the genotypes of coral hosts and their symbiotic Symbiodinium (van Oppen \& Gates 2006) that collectively inform the processes driving shifts in coral community structure. Where coral reefs have been quantitatively recorded with images, the opportunity remains for retrospective analyses motivated by emerging discoveries, but, in the case of genetic analyses, it is impossible to propose retrospective studies unless fortuitous pre-emptive sampling led to the preservation of historic tissue samples. The likelihood of such sampling on ecologically relevant time scales is low, and in cases where historic tissue samples in usable conditions are available, the opportunity to secure additional information from them must be fully exploited even if the original sampling was less comprehensive than modern-day science would suggest. Such was the case in the present study where single biopsies of 12 corals from 1994 were available.

The present study combines a $16 \mathrm{yr}$ analysis of coral reefs in St. John, US Virgin Islands (Edmunds 2013), with an initiative that began in 1994 to sample corals for genetic identity (Edmunds \& Elahi 2007). Our study focuses on the Tektite reef at $14 \mathrm{~m}$ depth in Great Lameshur Bay (18²18.585' N, 64²43.373' W), where the benthic community has been monitored since 1987 (Edmunds 2013). The reef consists of a buttress of Orbicella annularis (formerly Montastraea annularis [Budd et al. 2012]) growing in a columnarlobate morphology (Weil \& Knowlton 1994), with lobes capped by live $O$. annularis tissue and sides encrusted by algae and invertebrates. Adjacent lobes typically share a common skeleton but function autonomously (Hughes \& Jackson 1980), and hereafter are defined as colonies (after Connell 1973). Colonies undergo fission to produce multiple copies (ramets) of each host genotype (genets), but ramets and genets cannot be distinguished visually.

$O$. annularis and its relatives (i.e. O. franksi and $O$. faveolata) provide an interesting system to study variation in ecological performance and genetic diversity (of host and Symbiodinium), for this group of corals is the most important, widespread, and extensively studied hermatypic scleractinian in the tropical western Atlantic (Knowlton et al. 1992). Moroever, O. annularis has played a pivotal role in the paradigm shift that has changed the comprehension of the coral-zooxanthella symbiosis from a union containing a single type of algal cells to one hosting a diverse assemblage of Symbiodinium (Rowan \& Powers 1991, LaJeunesse 2001, Stat et al. 2008, Putnam et al. 2012). It was the $O$. annularis complex that provided the model system for some of the earliest analyses of ecologically meaningful variation of zooxanthella taxa (Rowan \& Knowlton 1995, Rowan et al. 1997), and this taxon has remained popular for the analysis of spatio-temporal variation in Symbiodinium for more than 2 decades (e.g. Garren et al. 2006, Thornhill et al. 2009, and references therein). Over this period it has become known as one of the most flexible corals with regard to the types of Symbiodinium harbored (Garren et al. 2006, Thornhill et al. 2009). Four clades (A, B, C, and D) of Symbiodinium (and multiple subtypes) have been found in the O. annularis complex (e.g. Rowan \& Knowlton 1995, Garren et al. 2006, Thornhill et al. 2006, 2009), together with intra-colony zonations of Symbiodinium clades (Rowan \& Knowlton 1995) that include variation among polyps (Kemp et al. 2008) and proportional changes in clade abundance over at least 6 yr (Thornhill et al. 2006).

Despite the research attention accorded to $O$. annularis, the opportunity has not been presented to combine concurrent measurements over multiple decades of holobiont performance, Symbiodinium diversity, or host identity. Such an opportunity was created by our work in St. John (Edmunds 2013), and in this paper we present the results of an analysis in which we combine ecological and genetic techniques to samples of $O$. annularis collected over $16 \mathrm{yr}$. While the 2 resulting sets of data each have limitations arising from methodology and demonic intrusion (sensu Hurlbert 1984), together they present a unique perspective to the processes potentially driving patterns of change on coral reefs in the Caribbean. For the 
ecological data, the methodological limitations are that the sampled colonies could not all be located in some of the $16 \mathrm{yr}$ of photoquadrats and that slight differences in camera orientation added to the variance in estimating colony area. For the genetic data, the methodological limitations were the small number of replicate colonies, the sampling of each colony with a single biopsy, and the potential for slight differences in biopsy position on the top of colonies at each sampling.

Tissue was sampled in 1994 from $O$. annularis at the long-term study site on Tektite reef, with the objective of describing the clonal population structure using DNA fingerprinting. Some samples were archived, and in 2010 we realized there was a unique opportunity to combine ecological monitoring of a coral population (i.e. with photoquadrats) with a retrospective and comparative analysis of host and Symbiodinium genotypes in these specific coral colonies at 2 times separated by $16 \mathrm{yr}$. We used the detailed records provided by the annual photoquadrats to track over time $12 \mathrm{O}$. annularis colonies that were sampled in 1994 for DNA, so that their tissues could again be biopsied in 2010 for DNA. The tissue samples from 1994 and 2010 were analyzed to explore the relationships among host genotype, Symbiodinium assemblages, and colony size (i.e. a measure of ecological success) with the assumption that a single sample of tissue from a standardized location on the colony surface is adequate to characterize host and Symbiodinium genotypes. Three hypotheses were tested: (1) Symbiodinium communities in O. annularis have not changed over time, (2) the relative abundance of Symbiodinium genotypes (mostly at the cladal level) is affected equally by the host genotype (the colony in which they are found) and location on the reef (i.e. the photoquadrat in which they are found), and (3) growth of $O$. annularis is independent of the genetic identity of Symbiodinium and the coral host.

\section{MATERIALS AND METHODS}

\section{Study site and ecology of Orbicella annularis}

The time-series analysis on the Tektite reef was based on 3 parallel $10 \mathrm{~m}$ transects along which 10 contiguous photoquadrats $(1 \times 1 \mathrm{~m})$ were recorded annually ( $\mathrm{n}=30$ photoquadrats $\mathrm{yr}^{-1}$ ). Transects crossed the flat upper surface of a single coral buttress and did not depart appreciably from $14 \mathrm{~m}$ depth across their length. Images were acquired on $35 \mathrm{~mm}$ film (Kodachrome 64) from 1987 to 2000, and digitally from 2001 to 2004 (3.34 megapixels) and 2005 to 2010 (6.1 megapixels). Refer to Edmunds (2013) and Edmunds \& Elahi (2007) for methodology. Images are archived (http://mcr.lternet.edu/vinp/overview/), and have been analyzed for percentage cover of the benthic community using CPCe software (Kohler \& Gill 2006). In addition to photoquadrats, seawater temperature has been recorded in Great Lameshur Bay since 1989, initially at $9 \mathrm{~m}$ depth at Yawzi Point ( 1 km away from the Tektite reef) from 1989 to 2011, and at the $14 \mathrm{~m}$ Tektite site since 2004. The temperature records used here include values from Yawzi Point from 1994 to 2003 and from Tektite from 2004 to 2009. Temperatures were recorded using a Ryan Industries Tempmentor $\left( \pm 0.3^{\circ} \mathrm{C}\right)$ from January 1992 to April 1997 and November 1997 to August 1999, an Optic Stowaway logger $\left( \pm 0.2^{\circ} \mathrm{C}\right.$ accuracy [Onset Industries]) at $9 \mathrm{~m}$ depth from May 1997 to October 1997 and from August 1999 to August 2001, and an Aquapro Logger $\left( \pm 0.2^{\circ} \mathrm{C}\right.$ accuracy [Onset Industries]) at $9 \mathrm{~m}$ depth from August 2001 to August 2010. Loggers recorded temperature every 15 to $30 \mathrm{~min}$, and these data were collapsed by day and described using the mean and interquartile ranges by year.

Colonies of Orbicella annularis were first sampled on 12 and 16 August 1994 for DNA fingerprinting. In 1994, biopsies of tissue and skeleton were collected in 2 photoquadrats using a $13 \mathrm{~mm}$ diameter steel punch. To prevent cross-contamination, a sterile punch was used for each colony and each biopsy was bagged individually underwater. Care was taken to sample biopsies from the horizontal upper surfaces of colonies, and the sampled holes were filled with nontoxic modeling clay. Photoquadrats were then photographed to allow sampled colonies to be located again and to evaluate the effects of sampling on these colonies. Biopsies were transported to the laboratory on ice ( $30 \mathrm{~min})$ and crushed in $2 \mathrm{ml}$ of ice-cold guanadinium hydrochloride (GHCl) buffer $(8 \mathrm{M} \mathrm{GHCl}$, $0.1 \mathrm{M}$ sodium acetate [pH 5.2], $5 \mathrm{mM}$ dithiothreitol, $0.5 \%$ N-lauryl sarcosine; Maniatis et al. 1989). After grinding, the slurry was stored at $4^{\circ} \mathrm{C}$ and transported at room temperature to California State University, Northridge (CSUN). Some samples were processed (Edmunds \& Elahi 2007), while others were stored at $4^{\circ} \mathrm{C}$ until 2010.

Between 5 and 8 August 2010 (i.e. virtually the same time of year as in 1994) the same colonies of $O$. annularis biopsied in 1994 were sampled with the objectives of genotyping the coral host and their Symbiodinium. To ensure identical colonies were sampled, the annual photoquadrats were used to 
track over time the shape, color, and orientation of the colonies first sampled in 1994. Based on the capacity to relocate colonies for which archived DNA from 1994 was available and the constraints of permits issued by the Virgin Island National Park, 12 colonies were tracked from 1994 to 2009. In 2010, laminated prints of the photoquadrats were used underwater to locate the same colonies for a second sampling and to ensure that the sampling orientations were the same as those employed 16 yr earlier. Sampling in the same position on each colony was important to reduce the likelihood that variation in Symbiodinium genotypes was caused by sampling different microhabitats across the colony surface (Rowan et al. 1997, Garren et al. 2006, Kemp et al. 2008). Our analysis therefore assumes that differences in Symbiodinium genotypes between the 2 samplings reflected the passage of time and not differences in sampling position within each colony.

In 2010, the 12 colonies of $O$. annularis were sampled using $6 \mathrm{~mm}$ diameter punches, and the holes were filled with non-toxic modeling clay. A sterile punch was used for each colony to prevent cross-contamination, and biopsies were bagged individually underwater, stored on ice, and returned to the laboratory for processing. Biopsies were stored in DNA extraction buffer (50\% [w/v] guanidinium isothiocyanate, $50 \mathrm{mM}$ Tris [pH 7.6], $10 \mu \mathrm{M}$ ethylenediaminetetraacetic acid [EDTA], 4.2\% [w/v] sarkosyl, and $2.1 \%$ [v/v] $\beta$-mercaptoethanol) and shipped at room temperature for processing at the University of Hawaii (Symbiodinium) or Florida State University (O. annularis host).

To evaluate growth, each of the 12 colonies was measured in the annual photoquadrats. Most colonies were found every year, although occasionally it was not possible to measure their size if they were obscured by the camera framer or gorgonians. Colonies were measured using ImageJ 1.42q software (Abramoff et al. 2004) to outline coral tissue and calculate planar area $\left(\mathrm{cm}^{2}\right)$. Each colony was tracked over $16 \mathrm{yr}$, and the trajectory of changing size was used as a measure of success. Success of the 12 colonies was placed in a broader context by evaluating overall coral cover using the 30 photoquadrats sampled annually. Coral cover was measured using CPCe software and a grid of 200 randomly located points on each image.

\section{DNA extraction}

Genomic DNA (coral host and Symbiodinium combined) was extracted following Pochon et al. (2001).
The 1994 samples were vortexed, and $200 \mu$ l of supernatant was placed in tubes with $400 \mu \mathrm{l}$ of guanidinium buffer. These tubes, as well as the crushed coral biopsies from 2010, were incubated at $72^{\circ} \mathrm{C}$ for $20 \mathrm{~min}$, centrifuged at $16000 \times g$ for $5 \mathrm{~min}$, and $300 \mu \mathrm{l}$ of the supernatant mixed with an equal volume of isopropanol was incubated at $-20^{\circ} \mathrm{C}$ overnight. DNA was precipitated by centrifugation at $16000 \times g$ for $15 \mathrm{~min}$, and the DNA pellet was washed in $70 \%$ ethanol, resuspended, and stored in Tris buffer $(0.1 \mathrm{M} \mathrm{pH} 8)$.

\section{Symbiodinium analysis}

Two genes from different cellular compartments (nuclear and chloroplastic), and 2 analytical approaches (cloning and pyrosequencing) were used to genotype the Symbiodinium in the 24 coral biopsies (12 each from 1994 and 2010). These approaches added the support of multiple markers and methodologies to tests of our hypotheses. Moreover, pyrosequencing provided more resolution to the analysis of temporal variation in Symbiodinium assemblages and its effects on holobiont performance in comparison to studies employing fingerprinting gel-based analysis. Previous studies have focused on banding patterns generated by using gel electrophoresis to separate DNA from Symbiodinium based on denaturing gradients (i.e. DGGE fingerprints) (LaJeunesse 2002, Pochon et al. 2007, Sampayo et al. 2009), and, while such approaches have good resolution for identifying dominant patterns, they have limited capacity to more finely resolve genetic variation or to detect rare genotypes. While interpreting the biological significance of rare Symbiodinium genotypes remains controversial in light of the presence of intragenomic variation associated with ITS2 (LaJeunesse \& Thornhill 2011, Stat et al. 2011), the increasing number of examples of Symbiodinium-host symbioses in which rare Symbiodinium genotypes have been found (Franklin et al. 2012, Green et al. 2014) argue strongly for using techniques with the resolution to detect such forms. This argument was compelling to us in the decision to expand our analytical approach to tag pyrosequencing of nrITS2 (nuclear ribosomal internal transcriber spacer 2) amplicons, as was the success of this approach in advancing other fields requiring fine-grained genetic resolution of single-celled organisms (Sogin et al. 2006). An important limitation of this early adoption of new techniques is we assume that the debate over the meaning of rare Symbiodinium genotypes will be resolved in favor of their biological significance. 
We PCR amplified the nuclear Internal Transcribed Spacer 2 (nrITS2) region and the chloroplastic 23S domain $\mathrm{V}$ (cp23S) region of the ribosomal arrays using the nrITS2 primers 'its-dino' and 'its2rev2' and the cp23S primers '23S4F' and '23S7R' (after Stat et al. 2009, Pochon \& Gates 2010). Each $50 \mu \mathrm{l}$ PCR reaction contained $1 \mu \mathrm{l}$ of DNA template, $5 \mu \mathrm{l}$ of $10 \times$ ImmoBuffer (Bioline), $0.2 \mu$ lMMOLASE ${ }^{\mathrm{TM}}$ Hot-Start DNA Polymerase (Bioline), $2 \mu \mathrm{l}$ of $50 \mathrm{mM} \mathrm{MgCl}_{2}, 1 \mu \mathrm{l}$ of $10 \mathrm{mM}$ total dNTPs (10 mM each), $1 \mu \mathrm{l}$ of each primer (10 pmol each), and $38.8 \mu \mathrm{l}$ of deionized sterile water. A touchdown PCR protocol was performed on a BioRad iCycler ${ }^{\mathrm{TM}}$ using the following conditions: $7 \mathrm{~min}$ at $95^{\circ} \mathrm{C}, 20$ cycles of $94^{\circ} \mathrm{C}$ for $30 \mathrm{~s}, 62^{\circ} \mathrm{C}$ for $30 \mathrm{~s}$ (decreased by $0.5^{\circ} \mathrm{C}$ at each cycle), $72^{\circ} \mathrm{C}$ for $1 \mathrm{~min}$, and followed by 12 additional cycles with an annealing temperature set at $52^{\circ} \mathrm{C}$, and a final extension of $72^{\circ} \mathrm{C}$ for $7 \mathrm{~min}$. PCR products were purified using the QIAquick ${ }^{\mathrm{TM}}$ PCR Purification Kit (Qiagen), and ligated into the pGEM-T Easy vector ${ }^{\mathrm{TM}}$ (Promega). A minimum of 10 positive inserts per clone library were amplified using plasmid-specific (M13) primers, and sequenced in both directions using the ABI Prism Big Dye $^{\mathrm{TM}}$ Terminator Cycle Sequencing Ready Reaction Kit and an ABI 3100 Genetic Analyzer (Perkin-Elmer Applied Biosystems). Bi-directional sequences were inspected and assembled using Sequencher V4.7 (Gene Codes Corporation) and aligned using BioEdit V7.0.5.3 (Hall 1999), and Symbiodinium were identified to clade and subclade level using the Basic Local Alignment SearchTool (BLAST) in nrITS2 and cp23S databases generated from sequences archived in GenBank (23 April 2013). This database is in Supplement 1 as a fasta file (www.int-res.com/articles/suppl/ m506p129_supp/).

The patterns of dominant-cloned Symbiodinium sequence types (i.e. the most abundant sequences in each sample) obtained using nrITS2 and cp23S were similar, but there were a few differences between the abundances in the cloned sequence numbers. This suggested that too few clones had been sequenced to fully capture the diversity of rare Symbiodinium sequence types. To address this issue, all DNA samples were re-sequenced using multiplexed tag pyrosequencing of the nrITS2 amplicons (described as pyrosequencing hereafter). This method, pioneered in the field of microbial ecology, is replacing cloning and DGGE as the technique of choice for addressing diversity (Huse et al. 2008) and has been successfully employed for characterizing cryptic Symbiodinium diversity within $O$. faveolata and $O$. franksi in the Gulf of Mexico (Green et al. 2014). We used pyrosequencing to increase the mean number of Symbio- dinium sequences acquired per coral sample from $\sim 10$ to $>1300$. For pyrosequencing, 24 nrITS2 Symbiodinium amplicon libraries were submitted to the Research and Testing Laboratory, LLC (Texas, USA) for analysis. Pyrosequencing involved ligating sample-specific tags for each of the 24 samples during the ITS2 amplification (cycling conditions described above, amplified separately from clone libraries), followed by amplicon purification, emulsion PCR, and high-throughput sequencing on a Roche GS FLX pyrosequencing system.

As described above, we acknowledge that ITS2 does not provide the correct characteristics for use as an alpha diversity marker. Prior work (e.g. Stat et al. 2011) has recognized the inability to link an individual biological entity to individual sequences due to duplication in the ribosomal array resulting in the production of paralogs that preclude species assignment. ITS2 can, however, be utilized in a comparative approach to determine patterns in the assemblage of sequences within a given sample. Our approach is primarily focused on identifying genetic variation over time and not on assigning taxonomy to the sequences identified. Reconciling both ecological patterns and taxonomic identify for Symbiodinium must be a high priority if the full biological significance of Symbiodinium diversity is to be appreciated for coral holobionts.

\section{Bioinformatic analysis of pyrosequencing results}

The 454 sequencing reads were trimmed to a $\mathrm{T}$ threshold of 25, clustered using USEARCH (Edgar 2010), chimera-checked using UCHIME (Edgar et al. 2011), and de-noised based on a quality score of 30 using a standard data analysis pipeline at the Research and Testing Laboratory, LLC. The full fasta file was demultiplexed and adapter-trimmed, and subsequently filtered to remove any terminal regions with a PHRED quality score $<20$. Sequences were filtered for lengths $>180 \mathrm{bp}$ and the maximum number of errors of 1 in the forward primer, and were trimmed of barcodes, adapters, and forward and reverse primers with Integroomer (http://courge.ics.hawaii.edu/inte/ groomer/). A Symbiodinium-specific bioinformatic pipeline (symTyper; M. Belcaid unpubl. method, https://github.com/bingo11/symTyper) was then employed to assign each Symbiodinium sequence an identity. Briefly, using HMMER V3 (http://hmmer. org/), the resulting sequences were compared to a database of Symbiodinium clade hidden Markov model profiles, which were generated from the ITS2 
database (Supplement 1). The sequencing reads were subsequently compared to each clade-specific profile, and a read was assigned to clade based on 2 rules: (1) the alignment was significant (e-value $\leq \mathrm{e}^{-20}$ with a sequence alignment over $95 \%$ of the read) and (2) the sequences were unlikely to have originated in another clade (e-value for the first hit was at least 5 orders of magnitude smaller than that of the second hit). Sequences failing the first rule were classified as unknown, whereas the sequences failing the second rule were considered ambiguous.

Reads that were successfully assigned to a clade were subsequently compared using BLAST in an nrITS2 database generated from sequences archived in GenBank (Supplement 1) and assigned the subtype of the reference with which they were most similar (97\% similarity over $97 \%$ of their length). Similar to the clade assignment stage, the non-ambiguity requirement was enforced by requiring that the first hit have a higher raw bit score than that of the second hit. Sequencing reads lacking pairwise similarity with database entries were classified as putatively new and were manually investigated for known systematic biases. Short sequences were dropped from the analysis, while ambiguous sequences aligning with similar quality to 2 or more subtypes were assigned to the lowest common ancestor node in the phylogenetic tree of its clade and reported to clade level only.

Each of the 3 steps described above: (1) clade assignment, (2) sequence subtyping, and (3) tree placement of ambiguous reads were implemented in a python program, available for download from the following github repository: https://github.com/bingo11/ symTyper.

\section{Host genetics}

Six microsatellite loci developed by Severance et al. (2004) were used to genotype the $O$. annularis host tissue. The PCR cocktail consisted of $2.4 \mu \mathrm{l} 5 \times$ PCR buffer (Promega), $1.2 \mu \mathrm{l} 1 \mathrm{mM}$ dNTPs, $0.15 \mu \mathrm{l} \mathrm{GoTaq,}$ $1.0 \mu \mathrm{l} 10 \mathrm{M}$ bovine serum albumin, 1.25 to $3.5 \mu \mathrm{l}$ $1.5 \mathrm{mM} \mathrm{MgCl}_{2}$ (depending on primer), $0.5 \mu \mathrm{l}$ of fluorescently labeled forward primer, $0.5 \mu \mathrm{l}$ reverse

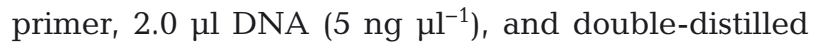
water to reach a total volume of $12 \mu \mathrm{l}$. PCR amplification was run as follows: $95^{\circ} \mathrm{C}$ for $3 \mathrm{~min}$, then 30 cycles of $95^{\circ} \mathrm{C}$ for $1 \mathrm{~min}, 50^{\circ} \mathrm{C}$ (primers maMS11, maMS2-4) or $55^{\circ} \mathrm{C}$ (primers maMS8, maMS12, maMS2-5, and maMS2-8) for $1 \mathrm{~min}, 72^{\circ} \mathrm{C}$ for $2 \mathrm{~min}$, then a final extension time of $30 \mathrm{~min}$ at $72^{\circ} \mathrm{C}$. PCR product from 3 loci with different fluorescent labels was multiplexed (multiplexI: maMS8, maMS2-4, maMS2-5; multiplexII: maMS11, maMS12, maMS2-8) using HiDI formamide (1:12), and $0.5 \mu \mathrm{l}$ was analyzed with Applied Biosystems 3130×l Genetic Analyzer with Capillary Electrophoresis. Genemapper software (Applied Biosystems, Vers. 4) was used to check for misidentified peaks and stutter bands. All alleles were binned into di- or tri-nucleotide sizes dependent on locus. Colonies with ambiguous genotypes were re-run to confirm binning. Loci were analyzed with MICRO-CHECKER software (van Oosterhout et al. 2004) to calculate the observed and expected heterozygosity and the likelihood of large allele drop-out and null alleles. The probability of colonies having identical genotypes via sexual reproduction (as opposed to being clonemates through asexual reproduction) was estimated using Gimlet (Valiere 2002).

\section{RESULTS}

\section{Study site and ecology of Orbicella annularis}

The Tektite reef had $40 \pm 3 \%$ coral cover in 1994, $49 \pm 3 \%$ in 2002 (the highest cover during the study), and $28 \pm 2 \%$ in 2010 (mean $\pm \mathrm{SE}, \mathrm{n}=30)$; Orbicella annularis was the dominant coral, accounting for an average of $67 \%$ of the coral cover between 1994 and 2010 (Fig. 1). Twelve colonies of $O$. annularis were followed over time in 2 photoquadrats (Fig. 2), and, at the time of sampling in both years, all colonies were visually indistinguishable in terms of color, overall morphology, and corallite size (Fig. 2, and Fig. S1 in Supplement 2 at www.int-res.com/articles/suppl/m506 p129_supp/). There were no apparent differences in reef morphology or physical conditions on this spatial scale, and, while the mean size $( \pm \mathrm{SE})$ of $O$. annularis colonies varied between Photoquadrats 1 (76 \pm $\left.11 \mathrm{~cm}^{2}, \mathrm{n}=8\right)$ and $2\left(132 \pm 52 \mathrm{~cm}^{2}, \mathrm{n}=4\right)$ in 1994 , the difference was not significant $(t=1.448, \mathrm{df}=10, \mathrm{p}=$ 0.179 ). The mean sizes of the 12 colonies were associated positively with coral cover (Fig. $1 C_{;} r=0.817, \mathrm{df}=$ $10, p=0.001$ ), and none died over the 16 yr. Eight colonies decreased in size by 41 to $82 \%$ between 1994 and 2009 (Fig. 1, and Table S1 in Supplement 2), with declines intensifying after 2002 in both photoquadrats. Three colonies grew by 4 to $68 \%$ between 1994 and 2009 (2 in Photoquadrat 1 and 1 in Photoquadrat 2) and represented 3 of the 4 smallest colonies in 1994. One colony was not measured in 2009 (though it was in 2008). Linear regressions of colony size on time were significant for 9 colonies $(F \geq 8.839$, df $=1, \geq 10$ 

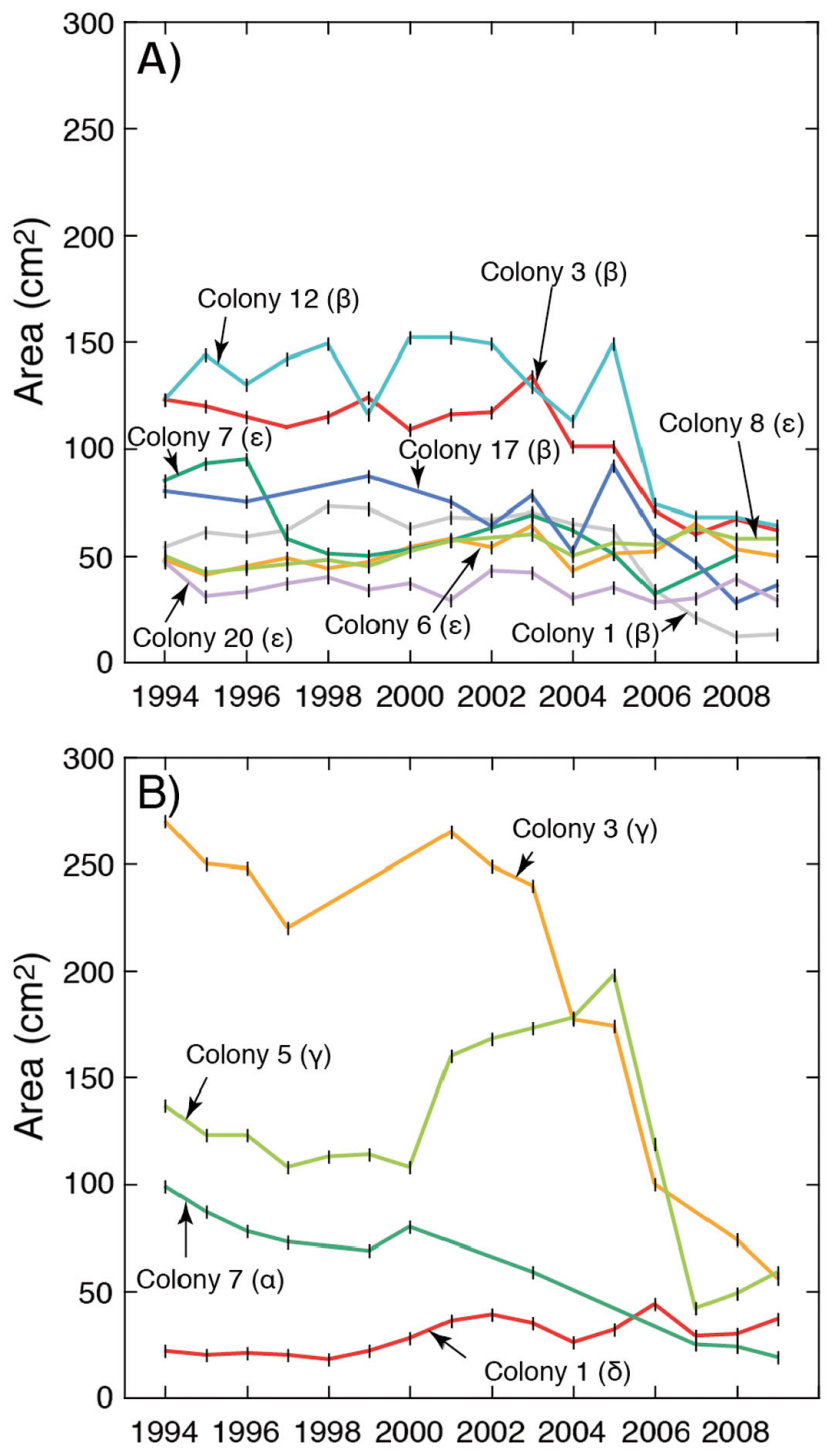

and $\leq 14, \mathrm{p} \leq 0.014$ ), but not for colonies 20 and 6 (Photoquadrat 1 ) or colony 5 (Photoquadrat 2$)(\mathrm{p}<0.050)$; colony 5 did not start to decline in size until 2006-07. Overall, the trajectories of change in size (regardless of statistical significance) ranged from $-12.6 \mathrm{~cm}^{2} \mathrm{yr}^{-1}$ (Colony 3, Photoquadrat 2) to $1.2 \mathrm{~cm}^{2} \mathrm{yr}^{-1}$ (Colony 1, Photoquadrat 2), with a mean rate of change of $-2.9 \pm$ $1.1 \mathrm{~cm}^{2} \mathrm{yr}^{-1}( \pm \mathrm{SE}, \mathrm{n}=12)$.

\section{Symbiodinium genetics}

Between 10 and 12 cloned Symbiodinium nrITS2 and cp23S sequences were obtained from each colony of $O$. annularis in 1994 and 2010, for a total of 264 nrITS2 and 269 cp23S sequences. The nrITS2 and cp23S cloned sequences predominantly belonged to Symbiodinium clades B and C (Fig. 3A,B). A single clade $\mathrm{D}$ sequence was found in 1 colony of $O$. annularis in 2010 (too low in abundance to register on Fig. 3B). The Symbiodinium clades detected in each coral using both markers were similar, but there were minor differences between markers for colonies 8, 17, and 20 in Photoquadrat 1 in 2010 (Table S1). In these 3 cases, additional clades were detected in lowabundance sequences, where a clade was identified with one marker but not the other. For example in colony 20 in 2010, all 12 cp23S sequences belonged to clade C Symbiodinium, but with nrITS2 10 sequences belonged to clade $\mathrm{C}$ and 1 to clade $\mathrm{B}$. As described above, such inconsistencies suggested that the number of clones sequenced was insufficient to fully visualize the low-abundance templates, and therefore rationalized the use of pyrosequencing.

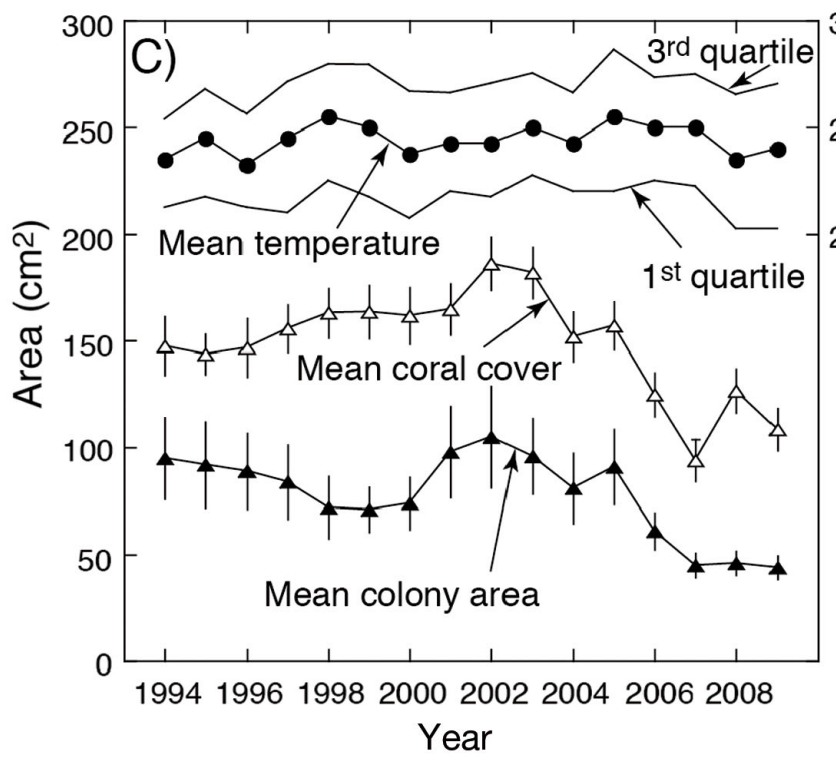

Fig. 1. Size of Orbicella annularis colonies from 1994 to 2009, coral cover, and seawater temperature. (A) Size of colonies $(1,3,6,7,8,12,17$, and 20) in Photoquadrat 1 and (B) size of colonies (1, 3, 5, and 7) in Photoquadrat 2. Colonies correspond in number, color, and Greek letters (marking host genotypes) to those displayed in Fig. 2, and Tables S1-S3 and Fig. S1 in Supplement 2 at www.int-res.com/ articles/suppl/m506p129_supp/. (C) Mean size $\left( \pm \mathrm{SE}, \mathrm{cm}^{2}\right)$ of colonies $(\boldsymbol{\Lambda}, \mathrm{n}=12$ colonies $)$, percentage overall coral cover (outer right ordinate; $\Delta, \mathrm{n}=30$ photoquadrats $\left.\mathrm{yr}^{-1}\right)$, and mean seawater temperature (inner right ordinate; $\bullet$ \pm SEs are smaller than symbols) based on daily records, with the interquartile range shown by adjacent lines 

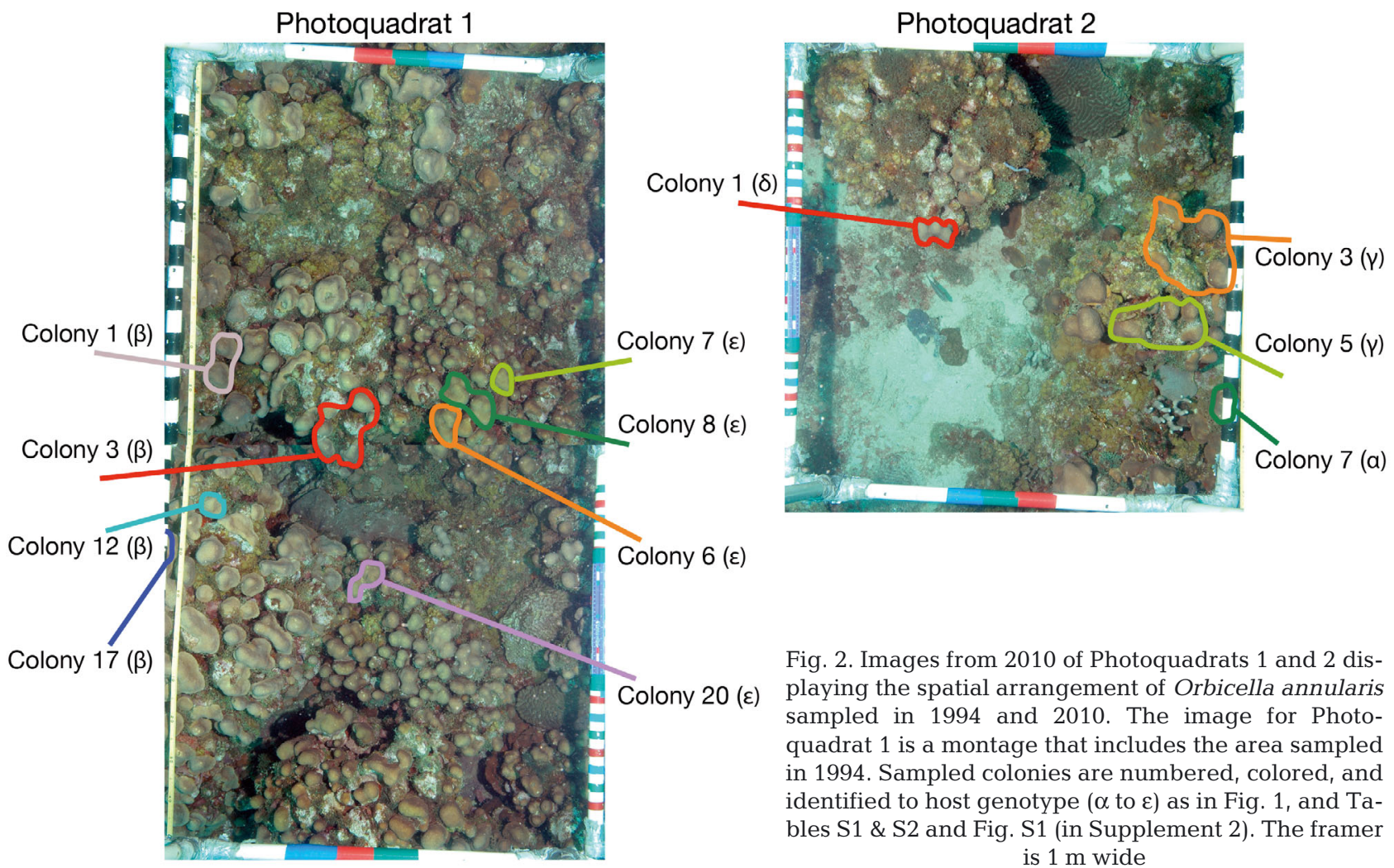

Fig. 2. Images from 2010 of Photoquadrats 1 and 2 displaying the spatial arrangement of Orbicella annularis sampled in 1994 and 2010. The image for Photoquadrat 1 is a montage that includes the area sampled in 1994. Sampled colonies are numbered, colored, and identified to host genotype ( $\alpha$ to $\varepsilon$ ) as in Fig. 1, and Tables S1 \& S2 and Fig. S1 (in Supplement 2). The framer is $1 \mathrm{~m}$ wide

Overall, clade-level analysis revealed that the proportional abundance of clade B and clade C Symbiodinium was dependent on sampling year for both cp23S $\left(\chi^{2}=18.058, \mathrm{df}=1, \mathrm{p}<0.001\right)$ and nrITS2 $\left(\chi^{2}=\right.$ $16.679, \mathrm{df}=1, \mathrm{p}<0.001)$. Analysis of cp23S revealed that clades B and C accounted for 10 and $90 \%$ of the sequences in 1994, respectively, whereas clade B increased to $30 \%$ and clade $\mathrm{C}$ decreased to $70 \%$ of the sequences in 2010 (Fig. 3A). The nrITS2 exhibited a very similar trend with clades $\mathrm{B}$ and $\mathrm{C}$ representing
(A) Chloroplastic 23C, cloning

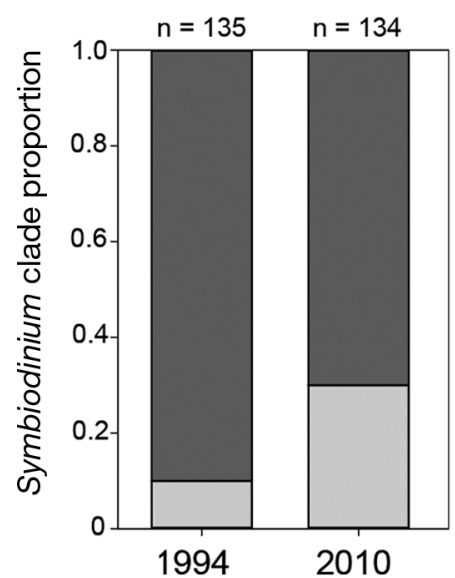

(B) Nuclear ITS2, cloning

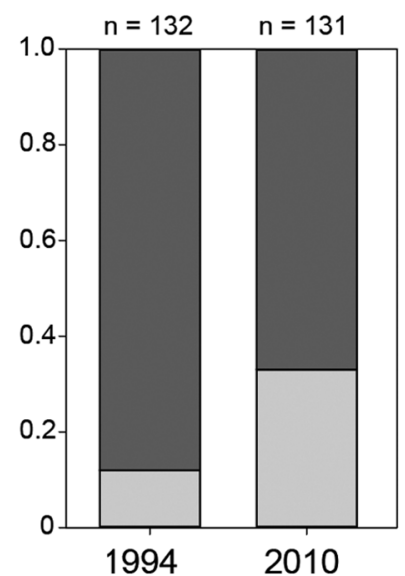

(C) Nuclear ITS2, pyrosequencing

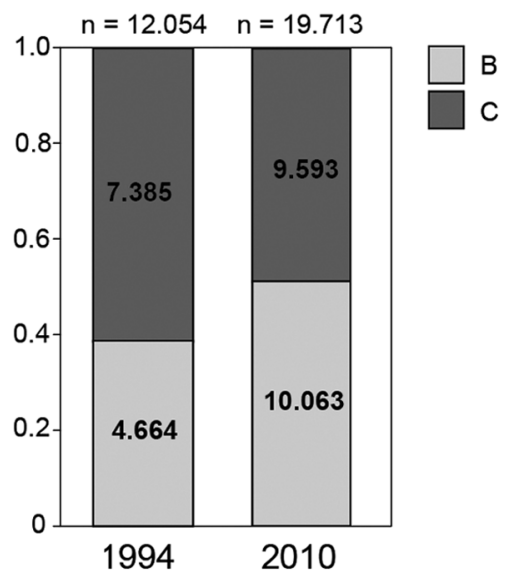

Fig. 3. Relative abundances of the dominant Symbiodinium clades B and C in Orbicella annularis colonies sampled in 1994 and 2010. The abundances are from (A) cloning chloroplastic 23S, (B) cloning nuclear ITS2, and (C) pyrosequencing nuclear ITS2. n: total number of sequences characterized (refer to Tables S2 \& S3 in Supplement 2 for details). Other Symbiodinium clades were present, but abundances were too low to appear in the figure $(<1 \%)$; these include 1 clade D sequence in the 2010 cloned nuclear ITS2 dataset and $0.2 \%$ of the sequences for clades A (34), F (12), and G (16) in the pyrosequenced nuclear ITS2 dataset (see Tables S2 \& S3 in Supplement 2) 
12 and $88 \%$ of the sequences in 1994, respectively, and clade $\mathrm{B}$ increasing to $33 \%$ and clade $\mathrm{C}$ decreasing to $67 \%$ of the sequences in 2010 (Fig. 3B) (clade $\mathrm{D}$ accounted for $0.8 \%$ of the sequences). Across the 2 sampling points, subclade level sequence identification included nrITS2 types C7, C12, B1, B101, and D1a (Franklin et al. 2012) and cp23S types cpC12 and cpB1 (сp nomenclature sensu Takabayashi et al. 2012). The fewer cp23S types recovered is consistent with the relatively low taxonomic resolution of this marker as compared to nrITS2.

Pyrosequencing of the nrITS2 region resulted in an average of $1324 \pm 142$ sequences per sample $( \pm \mathrm{SE})$, for a total of 31851 sequences; $99.7 \%$ were assigned to clade and $\sim 70 \%$ of these to subclade (Table 1 ). The shift in relative abundance of clade B and C Symbiodinium in corals sampled in 1994 and 2010 identified in the cloned cp23S and nrITS2 datasets were confirmed in the pyrosequenced nrITS2 dataset, but the relative abundance of clade B in 1994 and 2010 was higher than that detected using cloning (Fig. 3C). In addition to detecting clades $\mathrm{C}$ and $\mathrm{B}$, low numbers of clades $A, G$, and $F(<1 \%)$ were also detected using this approach (Table 1, and Table S3 in Supplement 2.

Clades B and C accounted for $99.8 \%$ of the pyrosequencing identified to clade level ( $\mathrm{n}=31$ 767; Table 1). The abundance of clade B and clade C Symbiodinium was again dependent on sampling year $\left(\chi^{2}=471.089\right.$, df $=1, \mathrm{p}<0.001$ ), with an increase in clade B in 2010 . Of the 12 O. annularis colonies sampled in 1994, 3 harbored only clade $\mathrm{C}$ and 9 had a mixture of clades $\mathrm{B}$ and $\mathrm{C}$ (Fig. 4, Table S1). Of these 9, 2 colonies (nos. 7 and 20) had more clade $B$ than clade $C$ sequences, and both of these colonies were found in Photoquadrat 1. In 2010, 2 colonies harbored only clade C, and 10 had a mixture of clades B and C. In contrast to 1994, however, 5 of the 10 mixed-clade colonies in 2010 had a greater abundance of clade B than clade C Symbiodinium; again these only occurred in Photoquadrat 1. In Photoquadrat 2, all 4 colonies remaining were dominated by clade C Symbiodinium, although a small number of clade B sequences $(2.4 \%)$ were found in colony 3 and 1 sequence was found in colony 7 (0.2\%) (Table S1). With regards to the rarer clades, no clade A Symbiodinium were detected in 1994, but clade A sequences were detected in 4 colonies in 2010 $(\leq 0.11 \%$ of all sequences; Table S1). Clade $\mathrm{G}$ and F sequences were also detected at low frequencies in 4 colonies $(<0.09 \%$ of all sequences $)-2$ in 1994 and 2 in 2010 (Table S1).

The BLAST analysis conducted to subtype for the pyrosequencing dataset revealed that clade B was dominated by B1 (79.7\%), B1.1122 (12\%), B10 (4.1\%), and B101 (1.5\%), 4 types that collectively represented $97.3 \%$ of the data for this clade (Table S3). The relative abundance of these types was dependent on sampling year (1994 versus 2010) $\left(\chi^{2}=28.030\right.$, df $=3$, $\mathrm{p}<0.001)$. All B types showed a pattern of increase in 2010, ranging from 1.9-fold in B1 to 2.7 -fold increases in B1.1122 (Table S3). Clade C was dominated by subclade types C7 (56.1\%), C12 (33.4\%), and C3.15 $(9.2 \%)$, which together accounted for $98.7 \%$ of the clade $\mathrm{C}$ sequences recovered. There was an overall shift in relative abundance between years when all 3 types were compared $\left(\chi^{2}=8.870, \mathrm{df}=2, \mathrm{p}=0.012\right)$, driven by an increase in the relative abundance of C3.15 in 2010. The relative proportion of subclades C7 and C12 (89.5\% of clade C) was consistent between years $\left(\chi^{2}=0.117\right.$, df $\left.=1, p=0.732\right)$, with C7 1.7fold more abundant than $\mathrm{C} 12$ in both years.

Table 1. Breakdown of nuclear ITS2 pyrosequencing results for clade and subclade level identification. Sequences were identified to clade by profiling against each clade within a comprehensive internal nuclear ITS2 database (M. Belcaid unpubl. method). Those filtered out at the clade level did not meet the cutoff values of $\mathrm{e}^{-20}$. Sequences were identified to subclade using BLAST and the internal ITS2 database, where the 'identified to type' category includes those hit with $>97 \%$ similarity and $>90 \%$ of the target length. The category 'unidentified to type' represents new sequences. Sequences filtered out at the subclade level represent those too short to identify ( $<90 \%$ of target length) or those occurring in abundance in $<3$ independent samples, as a conservative approach to minimize potential PCR or sequencing artifacts. ID: identified; UnID: unidentified

\begin{tabular}{|c|c|c|c|c|c|c|}
\hline \multirow[t]{2}{*}{ Clade } & \multicolumn{2}{|c|}{$\begin{array}{c}\text { Clade identification } \\
\text { Sequences entering analysis }=31851\end{array}$} & \multicolumn{4}{|c|}{$\begin{array}{l}\text { Subclade identification } \\
\text { Sequences entering analysis }=31767\end{array}$} \\
\hline & $\begin{array}{l}\text { Clade hits } \\
31767(99.7 \%)\end{array}$ & $\begin{array}{l}\text { Filtered out } \\
84(<1 \%)\end{array}$ & $\begin{array}{c}\text { ID to type } \\
22315(70.2 \%)\end{array}$ & $\begin{array}{l}\text { UnID to type } \\
6062(19.1 \%)\end{array}$ & $\begin{array}{l}\text { ID:UnID (\%) } \\
\mathrm{n}=28699\end{array}$ & $\begin{array}{l}\text { Filtered out } \\
3390(10.7 \%)\end{array}$ \\
\hline A & $<1$ & & $<1$ & $<1$ & $92.6: 7.4$ & \\
\hline B & 46.4 & & 43.0 & 69.6 & $69.5: 30.5$ & \\
\hline $\mathrm{C}$ & 53.4 & & 56.8 & 30.1 & $87.4: 12.6$ & \\
\hline F & $<1$ & & $<1$ & $<1$ & 9.1:90.9 & \\
\hline \multirow[t]{2}{*}{$\mathrm{G}$} & $<1$ & & $<1$ & $<1$ & $75: 25$ & \\
\hline & $100 \%$ & & $100 \%$ & $100 \%$ & & \\
\hline
\end{tabular}




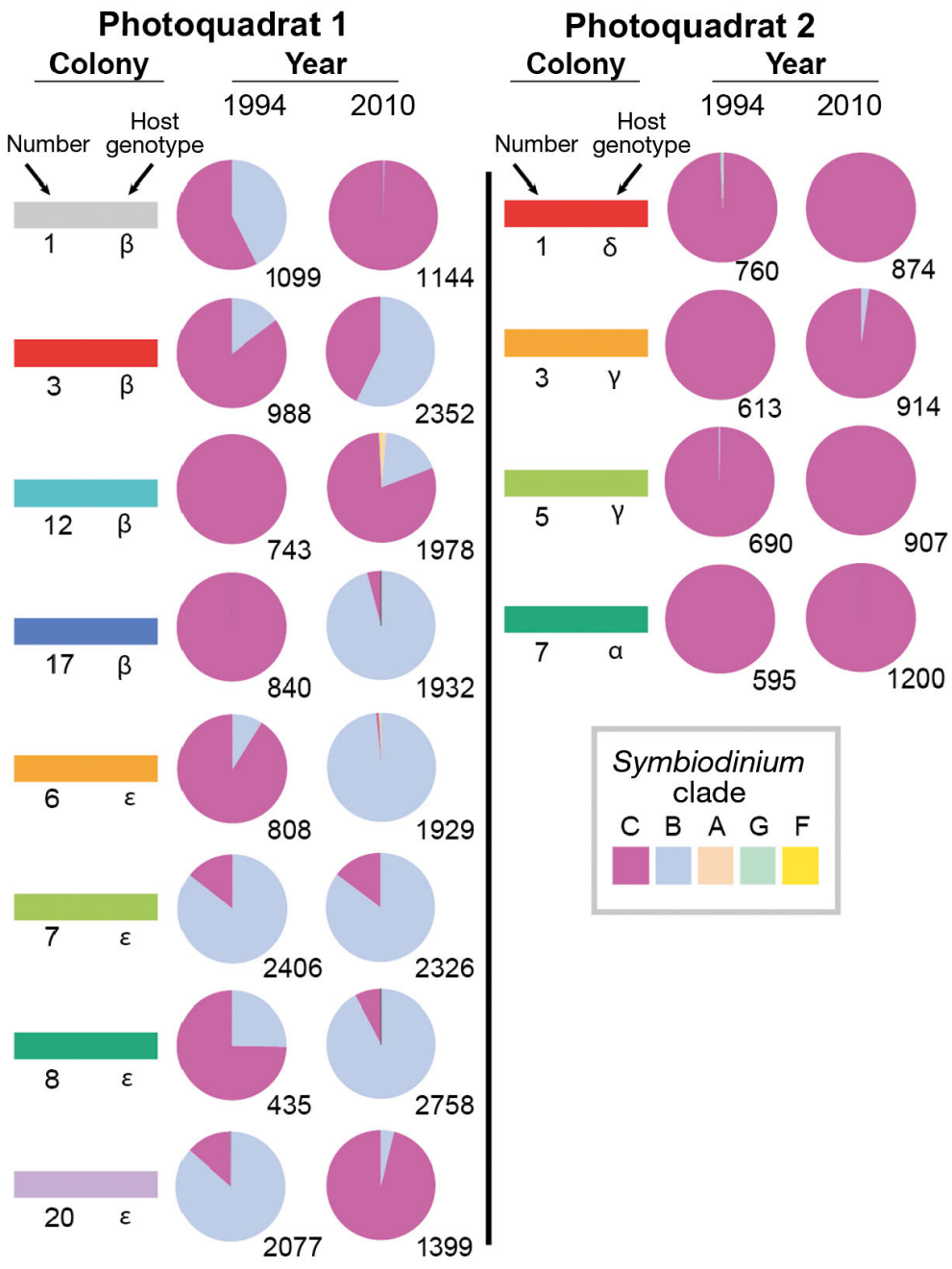

Fig. 4. Relative abundance of Symbiodinium clades in each colony of the Orbicella annularis sampled in 1994 and 2010 from Photoquadrats 1 and 2. Each colony is uniquely identified by the number in each photoquadrat and host genotype determined through the analysis of microsatellites (Greek letters), consistent with labeling schemes in Figs. $1 \& 2$, and Fig. S1 and Tables S1 \& S2 (in Supplement 2). Symbiodinium genotypes were identified by pyrosequencing nuclear ITS2, and the relative abundances of clades A, B, C, F, and G are shown. Clades A, F, and G were present in low abundances and are sometimes not visible on the pie charts (see Table S3 in Supplement 2 for details). Numbers of sequences per sample are shown below each pie chart

\section{Host genetics}

In the 12 colonies of $O$. annularis sampled in 2010, 1 locus was monomorphic (maMS8) and 1 failed to amplify consistently (maMS2-4) and was non-informative. The other 4 loci revealed 6 to 7 alleles. MicroChecker (van Oosterhout et al. 2004) indicated no evidence of deviations from null expectations or null alleles. The 4 variable loci provided support that individuals with the same genotype were not identical by descent (sexual reproduction), but via asexual cloning (Gimlet estimate of probability of sharing genotype by descent was 7.22 $\times 10^{-6}$ ). The host microsatellite loci indicated that the 12 colonies represented 5 genetic individuals, to which the Greek letters $\alpha$ to $\varepsilon$ were assigned (Fig. 2, Table S1). Photoquadrat 1 contained 8 colonies with 2 genotypes ( $\beta$ and $\varepsilon$ ), and Photoquadrat 2 contained 4 colonies with 3 genotypes $(\alpha, \gamma$, and $\delta)$.

\section{Synthesis}

Symbiodinium communities in coral host genotype $\beta$ (Photoquadrat 1) were dominated by clade $\mathrm{C}$ in 1994, and 2 of these 4 colonies shifted to dominance by clade B in 2010 (Fig. 4). Symbiodinium communities in host genotype $\varepsilon$ (Photoquadrat 1 ) were diverse, with 2 of the 4 colonies hosting more clade B than clade C Symbiodinium in 1994; by 2010, 3 of these colonies were dominated by clade B. The Symbiodinium communities in host genotypes $\alpha, \gamma$, and $\delta$ (4 colonies, Photoquadrat 2) were dominated by clade $\mathrm{C}$ in both years. In Photoquadrat 1 , clade $\mathrm{B}$ increased in abundance from 1994 to 2010, and independently in both host genotypes $\beta\left(\chi^{2}=\right.$ 111.002, df $=1, \mathrm{p}<0.001)$ and $\varepsilon\left(\chi^{2}=\right.$ 481.412, df $=1, \mathrm{p}<0.001$ ), but stayed at low background levels for all genotypes in Photoquadrat 2 (maximum 22 sequences in colony 3 ).

The change in size $\left(\mathrm{cm}^{2} \mathrm{yr}^{-1}\right)$ of the 12 colonies of $O$. annularis differed qualitatively among host genotypes (Fig. 5A), and differed significantly between genotypes $\beta$ and $\varepsilon$, for which 4 replicate colonies were recorded $(t=2.679, \mathrm{df}=6, \mathrm{p}=$ $0.037)_{i}$ colonies of genotype $\varepsilon$ barely declined in size, in contrast to colonies of genotype $\beta$. Colonies belonging to a single host genotype sometimes displayed contrasting growth trajectories with, for example, colonies 6 and 8 of genotype $\varepsilon$, increasing 4 to $16 \%$ between 1994 and 2009, whereas colonies 7 and 20 of the same genotype declined 38 to $41 \%$ (Fig. 1). Overall, colonies (pooled among host genotypes) changed in size at similar rates in Photoquadrats 1 and $2(t=$ $1.214, \mathrm{df}=10, \mathrm{p}=0.253$ ). Change in colony size was unaffected by the nrITS2 genetic composition of 

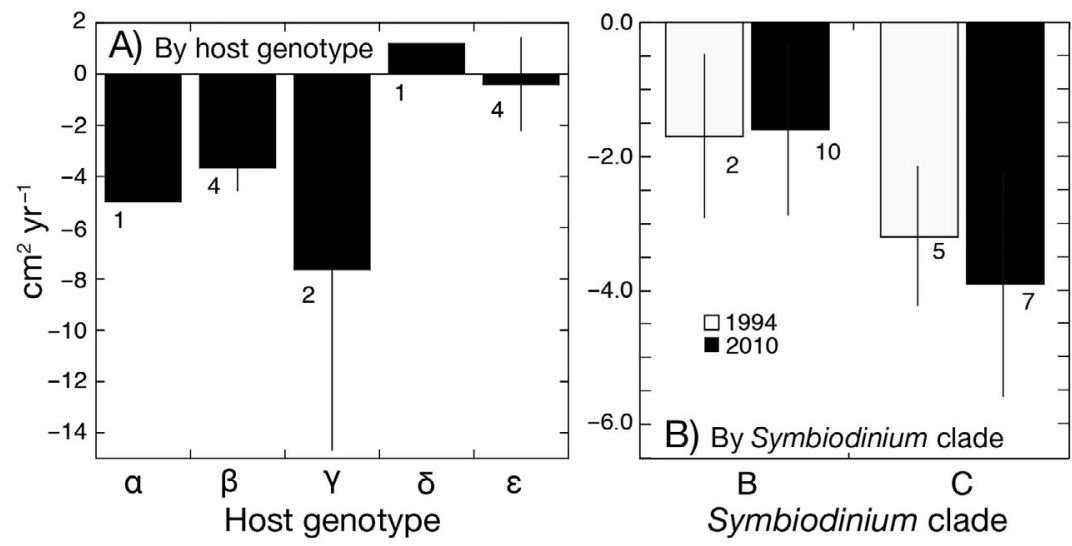

Fig. 5. Sixteen year growth trajectories (slopes of Model I regressions of size on time; $\mathrm{cm}^{2} \mathrm{yr}^{-1}$ ) for Orbicella annularis as a function of: (A) host genotypes, and (B) dominant Symbiodinium nuclear ITS2 clades determined by pyrosequencing. For Symbiodinium, growth trajectories are showed based on clade composition in 1994 (open bars) and 2010 (filled bars). Sample sizes are shown adjacent to each bar

Symbiodinium in 1994 (Mann-Whitney $U$-test, $U=$ $7.000, \mathrm{n}_{1}=10, \mathrm{n}_{2}=2, \mathrm{p}=0.519$ ) and 2010 (MannWhitney $U$-test, $U=12.000, \mathrm{n}_{1}=7, \mathrm{n}_{2}=5, \mathrm{p}=0.798$ ) (Fig. 5B), although of the 3 colonies with positive rates of change in size, $66 \%$ were dominated by clade B in 2010.

\section{DISCUSSION}

The growing number of anthropogenic assaults on the marine environment has impacts over a wide range of spatio-temporal scales, and will continue to affect biological systems for the foreseeable future. These assaults have focused attention on the value of high-resolution time-series analyses of biological systems to record the changes underway and guide effective resource management (Keitt 2008). With this focus, research once described pejoratively as surveillance monitoring (Nichols \& Williams 2006) has emerged as a mainstream approach (Nichols \& Williams 2006, Lindenmayer \& Likens 2010) that benefits from the largesse of governmental funding. This revision of research priorities has been striking for tropical coral reefs where decades of disturbances have reduced coral cover over large areas (Baker et al. 2008, De'ath et al. 2012), and the future threatens to bring more serious losses due to rising temperature and ocean acidification (van Hooidonk et al. 2014). Accordingly, time-series analyses of coral reef community structure have proliferated since the 1990s; yet it is still rare for the functional attributes of corals to be characterized in tandem with ecological monitoring to address processes underlying the patterns of change in community structure (Thornhill et al. 2006, Baker et al. 2013, Tonk et al. 2013).

\section{Have Symbiodinium in Orbicella annularis changed over 16 years?}

The present study focused on an ecologically dominant hermatypic coral and combined decadal-scale ecological surveys with genetic analyses to evaluate the extent to which the dynamics of individual colonies are associated with the genetic identity of the animal host and their algal symbionts (Symbiodinium). In so doing, we applied targeted monitoring (Nichols \& Williams 2006) to test 3 hypotheses relevant to identifying biological events associated with the change in coral community structure in one reef habitat on the south coast of St. John. First, we tested the hypothesis that genetic variants of Symbiodinium in Orbicella annularis have remained unchanged over 16 yr. This hypothesis was rejected, with a clear demonstration that the relative abundances of Symbiodinium clades and subclade types changed over time in the majority of coral colonies studied. The rapidly emerging descriptive landscape of phenotypic variation in Symbiodinium genotypes demonstrates the potential for coral success to be affected by the kinds of algal symbionts they harbor. For example, Symbiodinium genotypes differ in their photophysiology (Iglesias-Prieto et al. 2004, Warner et al. 2006), carbon fixation and translocation to the coral host (Stat et al. 2008, Cantin et al. 2009), and thermal tolerance (Rowan 2004, Warner et al. 2006). Moreover, variation in Symbiodinium genotypes is associated with the phenotypic traits of the holobiont, including susceptibility to disease (Stat et al. 2008, Correa et al. 2009) and colony growth (Little et al. 2004). The biological significance of our finding lies in demonstrating that the composition of the coral holobiont changed between 1994 and 2010. These changes provide a mechanistic rationale to infer that the functional capacity that these corals possessed in 2010 to respond to contemporary (and future) conditions is different from the capacity they possessed in 1994 to respond to previous conditions.

Our findings are, however, inconsistent with the directional and predictable shifts in Symbiodinium 
composition that might be anticipated by the adaptive bleaching hypothesis (ABH) (Buddemeier \& Fautin 1993). This hypothesis posits that bleaching provides a means for corals to change the composition of their Symbiodinium communities to maximize performance in the face of new conditions (Buddemeier \& Fautin 1993). Although initially met with resistance (Hoegh-Guldberg 1999), research has emerged demonstrating that at least some corals can acquire resistance to thermal stress through changes in the genetic composition of their Symbiodinium (Berkelmans \& van Oppen 2006, Jones et al. 2008), with members of clade D conferring resistance to high temperature (Berkelmans \& van Oppen 2006). There is, however, more to resisting environmental challenges than the capacity to change genetic variants of Symbiodinium, since symbiont flexibility (i.e. the capacity to contain a varied sequence assemblage of Symbiodinium) appears to be a trait associated with species of corals that are sensitive to environmental conditions (Putnam et al. 2012). Moreover, host tissue alone plays an important role in resisting bleaching stressors (Baird et al. 2009).

Although the sampling for Symbiodinium genotypes in our study is temporally sparse, our findings are inconsistent with the $\mathrm{ABH}$, particularly since the 1994 and 2010 samplings spanned a period characterized by warming seawater with several exceptionally warm years (Fig. 1C) that were associated with thermal bleaching (McWilliams et al. 2005) and, on the study reef, outbreaks of bleaching and coral disease affecting $O$. annularis (Miller et al. 2009). Of the 8 corals in Photoquadrat 1, 7 showed changes in Symbiodinium community composition between 1994 and 2010, with the trend most conspicuous for the increased prevalence of clade B in 2010. Less than $5 \mathrm{~m}$ away in Photoquadrat 2, all 4 sampled corals showed the reverse trend of stability in Symbiodinium community composition, hosting clade C almost exclusively in both years. Shifts in Symbiodinium community composition to favor clade B are perhaps unsurprising given reports that clades $\mathrm{A}$ and B typically dominate the upper surfaces of $O$. annularis in shallow water (Rowan et al. 1997, Toller et al. 2001a, Thornhill et al. 2006). Nevertheless, in the context of the $\mathrm{ABH}$, it is noteworthy that patterns of change in Symbiodinium communities differed in colonies separated by only a few meters in a uniform habitat and that there was a low occurrence of at least 1 thermally resistant clade (i.e. D in 2010) (Berkelmans \& van Oppen 2006). These observations must, however, be interpreted with caution, as we have no knowledge of how Symbiodinium clades changed in abundance in the 16 yr between samplings, and it is impossible to know what selective forces elicited the changes we observed in 2010, or the adaptive consequences with regards to tolerance to thermal regimes.

\section{Factors associated with changes in Symbiodinium community composition}

Our second objective was to test the hypothesis that Symbiodinium community composition was affected equally by the host genotype and the location of each colony on the reef. This analysis was opportunistic in that host genotypes were not selected for analysis a priori and the spatial analysis contrasted photoquadrats spatially separated by $\sim 5 \mathrm{~m}$. This hypothesis was, however, also rejected. Our results showed that variation in Symbiodinium community composition in $O$. annularis in St. John was more strongly influenced by location on the reef on a scale of meters than by host genotype. Given the apparent spatial homogeneity of the reef where the study was conducted, we foresaw no physical driver of variation in Symbiodinium genotypes on a scale of meters, even though variation at this spatial scale has been found among colonies of Montipora capitata in Hawaii (Stat et al. 2011, but see LaJeunesse \& Thornhill 2011) and Acropora millepora on a single reef flat (Jones et al. 2008). While discordant environmental conditions over the surface of mounding corals creates opportunities for variation in Symbiodinium genotypes (Rowan et al. 1997, Garren et al. 2006), such effects are unlikely to have influenced the Symbiodinium communities in the present study because care was taken to sample corals in similar locations on the upper surface of all colonies. This does not, however, exclude the possibility that micro-scale variation (e.g. among polyps) in Symbiodinium genotypes confounded our contrast of Symbiodinium genotypes in 1994 and 2010, although there is no evidence that such variation occurs on the relatively smooth upper surfaces of $O$. annularis on the Tektite reef of St. John. Variation in Symbiodinium genotypes among closely spaced polyps has been detected using syringe-needle sampling on Orbicella faveolata from Belize (Kemp et al. 2008), and application of this technique to $O$. annularis in St. John would be valuable in determining how much of the variation in Symbiodinium genotypes between 1994 and 2010 was caused by polyp-scale differences in sampling location within individual colonies. 
Many of the Symbiodinium types encountered in the present study, including C7, C12, C3, B1, B10, and $\mathrm{A} 3$, have previously been reported in the $O$. annularis species complex, and show zonation as a function of depth and position on the colony surface, with clade $\mathrm{C}$ typically more abundant at greater depths and in shaded microhabitats (Rowan et al. 1997, Garren et al. 2006, Thornhill et al. 2006, 2009, Warner et al. 2006). The apparent temporal stability of clade C type Symbiodinium in Photoquadrat 2, yet strong shifts in types and relative abundances just $5 \mathrm{~m}$ away in Photoquadrat 1, is inconsistent with these previous studies and suggests factors independent of depth contributed to the Symbiodinium community composition. Assuming that the physical conditions defining the optimal niches for Symbiodinium success - for example, light intensity, seawater temperature, and nutrients (Cooper et al. 2011, Tonk et al. 2013) — are similar on the upper surfaces of conspecific colonies across a topographically uniform reef at a constant depth and that the host genotype has relatively little effect on the types or abundances of Symbiodinium genotypes (this study), then location-specific variation in Symbiodinium genotypes could arise from at least 3 sources.

First, stochastic processes (Stat et al. 2011) could influence Symbiodinium genetic structure by the random supply of genotypes to coral hosts. Secondly, the hidden effects of history could determine genetic variation in Symbiodinium as a result of events occurring prior to sampling in 1994, or between the 2 samplings in 1994 and 2010. And third, biotic processes unique to each photoquadrat and independent of $O$. annularis colonies could indirectly influence Symbiodinium community composition in the corals. Such processes could include non-scleractinian sources and sinks of Symbiodinium genotypes (Takabayashi et al. 2012), or biological events indirectly affecting the interaction of coral hosts and Symbiodinium (e.g. Jeong et al. 2012). Bleaching and coral diseases can also mediate changes in the association between the coral host and its symbionts (Toller et al. 2001b), and, interestingly, a severe outbreak of bleaching and subsequent coral disease occurred on the Tektite reef in 2005 (Miller et al. 2009). These events ultimately led to a $53 \%$ reduction in coral cover between 2005 and 2006 over the entire Tektite reef (which included an area larger than that sampled here) (Miller et al. 2009). Conceivably, therefore, the differences in the Symbiodinium found in $O$. annularis in 2010 versus 1994 could reflect a persistent response to bleaching and disease in 2005, with the patchiness of these phenomena driving the small- scale spatial variation we detected in 2010 for Symbiodinium types found in closely spaced colonies of O. annularis. While the present study cannot distinguish among the aforementioned possibilities, our results suggest that the compositions of Symbiodini$u m$ communities in $O$. annularis at this location are strongly influenced by extrinsic processes.

\section{Do variants of Symbiodinium affect the growth of Orbicella annularis?}

Finally, we tested the hypothesis that the growth of $O$. annularis is independent of the genetic identity of Symbiodinium and the animal host. This hypothesis was rejected, and our results demonstrated that the growth of $O$. annularis differed among host genotypes and showed a weak trend to vary depending on the genetic complement of Symbiodinium. The effect of host genotype reinforces earlier studies emphasizing the importance of phenotypic variation among clonal genotypes of corals (Bruno \& Edmunds 1997), and, in the present case, reveals a mechanism that could potentially drive shifting abundances of host genotypes over time. Based on the growth rates of the 5 host genotypes that were resolved, genotypes $\delta$ and $\varepsilon$ would likely be the only 2 to thrive in the future, with the other 3 locally extirpated. This result is similar to that found in other Orbicella spp. where corals with higher biomass survived following bleaching (Thornhill et al. 2011). Genotype $\varepsilon$ corals had the highest proportion of clade B symbionts in 2010, a trend that encapsulated the greatest withingenotype Symbiodinium shift from clade C to clade B. While not statistically significant, it is striking that corals containing a predominantly clade B Symbiodinium represented $66 \%$ of the corals that displayed positive trajectories of changing size over 16 yr.

\section{Summary and future work}

This study reveals the benefits that can be realized by combining routine ecological tools of coral reef monitoring with contemporary techniques to characterize the genetic identity of the dominant corals and their Symbiodinium symbionts. We have been able to combine what has become a common pattern on tropical coral reefs-declining coral cover and shrinking coral colonies - with a process-oriented analysis to shed light on the association between genetic variation in the coral host, genetic diversity of Symbiodinium symbionts, and changes in coral pop- 
ulation structure. In light of our results, it may be timely to focus attention on the role of reef microenvironments in affecting the Symbiodinium complement of corals and to evaluate the conditions under which the Symbiodinium complement has the strongest effect on holobiont phenotype. Further, given the advances made here through the analysis of legacy tissue samples fortuitously preserved with DNA analyses in mind, it might be valuable to consider archiving coral tissue samples in concert with ongoing major coral reef monitoring efforts. Finally, the present analysis underscores the importance of resolving the biological significance of rare genotypes in Symbiodinium communities within coral hosts and of reaching a consensus regarding the best analytical tools for this task.

Acknowledgements. This research was funded through the US National Science Foundation program, Long-Term Research in Environmental Biology (to P.J.E., DEB 03-43570 and DEB 08-51441), and was completed under permits issued by the Virgin Islands National Park (most recently VIIS2010-SCI-0020 and VIIS-2010-SCI-0011). Funding from the US Office of Naval Research supported sampling in 1994 (N00014-93-1-0440) and funding from the New Zealand Ministry of Business, Innovation and Employment (Contract CAWX1208) supported X. Pochon during manuscript preparation. We are grateful to R. Boulon and C. S. Rogers for supporting our research in St. John; V. Powell and S. Prosterman for assistance with logistics; L. Jacobson, D. Brown, and C. Ross for field assistance in 2010; N. Colvard, who analyzed images to support Fig. 1; and the staff of the Virgin Islands Environmental Resources Station for making our visits productive and enjoyable. Comments from 2 anonymous reviewers improved an earlier draft of this paper. This is Contribution Number 210 of the Marine Biology Program of California State University, Northridge; Contribution Number 1589 of the Hawaii Institute of Marine Biology (HIMB); and Contribution Number 9125 of the School of Ocean and Earth Science and Technology (SOEST).

\section{LITERATURE CITED}

Abramoff MD, Magalhaes PJ, Ram SJ (2004) Image processing with Image J. Biophotonics 11:36-42

Baird AH, Guest JR, Willis BL (2009) Systematic and biogeographical patterns in the reproductive biology of scleractinian corals. Annu Rev Ecol Evol Syst 40:551-571

Baker AC, Glynn PW, Riegl B (2008) Climate change and coral reef bleaching: an ecological assessment of longterm impacts, recovery trends and future outlook. Estuar Coast Shelf Sci 80:435-471

Baker DM, Weigt L, Fogel M, Knowlton N (2013) Ancient DNA from coral-hosted Symbiodinium reveal a static mutualism over the last 172 years. PLoS ONE 8:e55057

Berkelmans R, van Oppen MJH (2006) The role of zooxanthellae in the thermal tolerance of corals: a 'nugget of hope' for coral reefs in an era of climate change. Proc Biol Sci 273:2305-2312
Bruno JF, Edmunds PJ (1997) Clonal variation for phenotypic plasticity in the coral Madracis mirabilis. Ecology 78:2177-2190

> Budd AF, Fukami H, Smith ND, Knowlton N (2012) Taxonomic classification of the reef coral family Mussidae (Cnidaria: Anthozao: Scleractinia). Zool J Linn Soc 166: 465-529

> Buddemeier RW, Fautin DG (1993) Coral bleaching as an adaptive mechanism. Bioscience 43:320-326

> Cantin NE, van Oppen MJH, Willis BL, Mieog JC, Negri AP (2009) Juvenile corals can acquire more carbon from highperformance algal symbionts. Coral Reefs 28:405-414

Connell JH (1973) Population ecology of reef-building corals, Vol 2. In: Jones OA, Endean R (eds) Biology and geology of coral reefs. Academic Press, New York, NY, p 204-245

Cooper TF, Berkelmans R, Ulstrup KE, Weeks S, Radford B, Jones AM, Goyle J, Canto M, O'Leary RA, van Oppen MJH (2011) Environmental factors controlling the distribution of Symbiodinium harboured by the coral Acropora millepora on the Great Barrier Reef. PLoS ONE 6: e25536

> Correa AMS, Brandt ME, Smith TB, Thornhill DJ, Baker AC (2009) Symbiodinium associations with diseased and healthy scleractinian corals. Coral Reefs 28:437-448

> De'ath G, Fabricius KE, Sweatman H, Puotinen M (2012) The 27-year decline of coral cover on the Great Barrier Reef and its causes. Proc Natl Acad Sci USA 109: 17995-17999

> Edgar RC (2010) Search and clustering orders of magnitude faster than BLAST. Bioinformatics 26:2460-2461

- Edgar RC, Haas BJ, Clemente JC, Quince C, Knight R (2011) UCHIME improves sensitivity and speed of chimera detection. Bioinformatics 27:2194-2200

$>$ Edmunds PJ (2013) Decadal-scale changes in the community structure of coral reefs in St. John, US Virgin Islands. Mar Ecol Prog Ser 489:107-123

> Edmunds PJ, Elahi R (2007) The demographic of a 15-year decline in cover of the Caribbean reef coral Montastraea annularis. Ecol Monogr 77:3-18

Franklin EC, Stat M, Pochon X, Putnam HM, Gates RD (2012) GeoSymbio: a hybrid cloud-based web application of global geospatial bioinformatics and ecoinformatics for Symbiodinium-host symbioses. Mol Ecol Resour 12:369-373

> Garren M, Walsh SM, Caccone A, Knowlton N (2006) Patterns of association between Symbiodinium and members of the Montastraea annularis complex on spatial scales from within colonies to between geographic regions. Coral Reefs 25:503-512

> Goreau TF (1959) The ecology of Jamaican coral reefs. I. Species composition and zonation. Ecology 40:67-90

Gosz JR, Waide RB, Magnuson JJ (2010) Twenty-eight years of the US-LTER program: experience, results, and research questions. In: Muller F, Baessler C, Schubert $\mathrm{H}$, Klotz $\mathrm{S}$ (eds) Long-term ecological research. Springer Sciences + Business Media BV, p 59-74

> Green EA, Davies SW, Matz MV, Medina M (2013) Nextgeneration sequencing reveals cryptic Symbiodinium diversity within Orbicella faveolata and Orbicella franksi at the Flower Garden Banks, Gulf of Mexico. PeerJ 2:e386

> Hairston NJ, Ellner SP, Geber MA, Yoshida T, Fox JA (2005) Rapid evolution and the convergence of ecological and evolutionary time. Ecol Lett 8:1114-1127 
Hall TA (1999) BioEdit: a user-friendly biological sequence alignment editor and analysis program for Windows 95/98/NT. Nucleic Acids Symp Ser 41:95-98

> Hoegh-Guldberg O (1999) Coral bleaching, climate change and the future of the world's coral reefs. Mar Freshw Res 50:839-866

> Hoegh-Guldberg O, Mumby PJ, Hooten AJ, Steneck RS and others (2007) Coral reefs under rapid climate change and ocean acidification. Science 318:1737-1742

$>$ Hughes TP, Jackson JBC (1980) Do corals lie about their age? Some demographic consequences of partial mortality, fission, and fusion. Science 209:713-715

> Hurlbert SH (1984) Pseudoreplication and the design of ecological field experiments. Ecol Monogr 54:187-211

> Huse SM, Dethlefsen L, Huber JA, Mark Welch D and others (2008) Exploring microbial diversity and taxonomy using SSU rRNA hypervariable tag sequencing. PLoS Genet 4: e1000255

Iglesias-Prieto R, Beltran VH, LaJeunesse TC, Reyes-Bonilla $\mathrm{H}$, Thome PE (2004) Different algal symbionts explain the vertical distribution of dominant reef corals in the eastern Pacific. Proc Biol Sci 271:1757-1763

> Jablonski D, Sepkoski JJ (1996) Paleobiology, community ecology, and scales of ecological pattern. Ecology 77 : 1367-1378

> Jeong HJ, Yoo YD, Kang NS, Lim AS and others (2012) Heterotrophic feeding as a newly identified survival strategy of the dinoflagellate Symbiodinium. Proc Natl Acad Sci USA 109:12604-12609

Jones AM, Berkelmans R, van Oppen MJH, Mieog JC, Sinclair W (2008) A community change in the algal endosymbionts of a scleractinian coral following a natural bleaching event: field evidence of acclimatization. Proc Biol Sci 275:1359-1365

Keitt TH (2008) Coherent ecological dynamics induced by large-scale disturbance. Nature 454:331-334

Kemp DW, Fitt WK, Schmidt GW (2008) A microsampling method for genotyping coral symbionts. Coral Reefs 27 : 289-293

Knowlton N, Weil E, Leigt LA, Guzman HM (1992) Sibling species in Montastraea annularis, coral bleaching, and the coral climate record. Science 255:330-333

Kohler KE, Gill SM (2006) Coral point count with excel extensions (CPCe): a visual basic program for the determination of coral and substrate coverage using random point count methodology. Comput Geosci 32:1259-1269

LaJeunesse TC (2001) Investigating the biodiversity, ecology, and physiology of endosymbiotic dinoflagellates in the genus Symbiodinium using the ITS region: in search of a 'species' level marker. J Phycol 37:866-880

- LaJeunesse TC (2002) Diversity and community structure of symbiotic dinoflagellates from Caribbean coral reefs. Mar Biol 141:387-400

LaJeunesse TC, Thornhill DJ (2011) Improved resolution of reef-coral endosymbiont (Symbiodinium) species diversity, ecology, and evolution through psbA non-coding region genotyping. PLoS ONE 6:e29013

Lindenmayer DB, Likens GE (2010) The science and application of ecological monitoring. Biol Conserv 143:1317-1328

> Little AF, van Oppen NJH, Willis BL (2004) Flexibility in algal endosymbioses shapes growth in reef corals. Science 304:1492-1494

Loya Y (1972) Community structure and species diversity of hermatypic corals at Eilat, Red Sea. Mar Biol 13:100-123 Maniatis T, Fritsch E, Sambrook J (1989) Molecular cloning; a laboratory manual. Cold Spring Harbor Press, Princeton, NJ

McWilliams JP, Cote IM, Gill JA, Sutherland WJ, Watkinson AR (2005) Accelerating impacts of temperature induced corals bleaching in the Caribbean. Ecology 86:2055-2060

Miller J, Muller E, Rogers C, Waara R and others (2009) Coral disease following massive bleaching in 2005 causes $60 \%$ decline in coral cover on reefs in the US Virgin Islands. Coral Reefs 28:925-937

Nichols JD, Williams BK (2006) Monitoring for conservation. Trends Ecol Evol 21:668-673

> Pochon X, Gates RD (2010) A new Symbiodinium clade (Dinophyceae) from soritid foraminifera in Hawai'i. Mol Phylogenet Evol 56:492-497

> Pochon X, Pawlowski J, Zaninetti L, Rowan R (2001) High genetic diversity and relative specificity among Symbiodinium-like endosymbiotic dinoflagellates in soritid foraminiferans. Mar Biol 139:1069-1078

Pochon X, Garcia-Cuetes L, Baker AC, Castella E, Pawlowski J (2007) One-year survey of a single Micronesian reef reveals extraordinary rich diversity of Symbiodinium types in soritid foraminifera. Coral Reefs 26:867-882

> Putnam HM, Stat M, Pochon X, Gates RD (2012) Endosymbiotic flexibility associated with environmental sensitivity in scleractinian corals. Proc Biol Sci 279:4352-4361

Rowan R (2004) Thermal adaptations in reef coral symbionts. Nature 430:742

> Rowan R, Knowlton N (1995) Intraspecific diversity and ecological zonation in coral-algal symbiosis. Proc Natl Acad Sci USA 92:2850-2853

Rowan R, Powers DA (1991) Molecular genetic identification of symbiotic dinoflagellates (zooxanthellae). Mar Ecol Prog Ser 71:65-73

Rowan R, Knowlton N, Baker A, Jara J (1997) Landscape ecology of algal symbionts creates variation in episodes of coral bleaching. Nature 388:265-269

Sampayo EM, Dove S, LaJeunesse TC (2009) Cohesive molecular genetic data delineate species diversity in the dinoflagellate genus Symbiodinium. Mol Ecol 18:500-519

Severance EG, Szmant AM, Karl SA (2004) Single-copy gene markers isolated from the Caribbean coral Montastraea annularis. Mol Ecol Notes 4:167-169

Sogin ML, Morrison HG, Huber JA, Welch DM and others (2006) Microbial diversity in the deep sea and the underexplored 'rare biosphere'. Proc Natl Acad Sci USA 103: 12115-12120

> Stat M, Morris E, Gates RD (2008) Functional diversity in coral-dinoflagellate symbiosis. Proc Natl Acad Sci USA 105:9256-9261

> Stat M, Pochon X, Cowie ROM, Gates RD (2009) Specificity in communities of Symbiodinium in corals from Johnston Atoll. Mar Ecol Prog Ser 386:83-96

- Stat M, Bird CE, Pochon X, Chasqui L and others (2011) Variation in Symbiodinium ITS2 sequence assemblages among coral colonies. PLoS ONE 6:e15854

> Takabayashi M, Adams L, Pochon X, Gates RD (2012) Genetic diversity of free-living Symbiodinium in surface water and sediment of Hawai'i and Florida. Coral Reefs 31:157-167

> Thornhill DJ, LaJeunesse TC, Kemp DW, Fitt WK, Schmidt GW (2006) Multi-year, seasonal genotypic surveys of coral-algal symbioses reveal prevalent stability or postbleaching reversion. Mar Biol 148:711-722

Thornhill DJ, Xiang Y, Fitt WK, Santos SR (2009) Reef endemism, host specificity and temporal stability in pop- 
ulations of symbiotic dinoflagellates from two ecologically dominant Caribbean corals. PLoS ONE 4:e6262

Thornhill DJ, Rotjan RD, Todd BD, Chilcoat GC and others (2011) A connection between colony biomass and death in Caribbean reef-building corals. PLoS ONE 6:e29535

Toller WW, Rowan R, Knowlton N (2001a) Zooxanthellae of the Montastraea annularis species complex: patterns of distribution of four taxa of Symbiodinium on different reefs and across depths. Biol Bull 201:348-359

Toller WW, Rowan R, Knowlton N (2001b) Repopulation of zooxanthellae in the Caribbean corals Montastraea annularis and $M$. faveolata following experimental and disease-associated bleaching. Biol Bull 201:360-373

Tonk L, Sampayo EM, Weeks S, Magno-Canto M, HoeghGuldberg O (2013) Host-specific interactions with environmental factors shape the distribution of Symbiodinium across the Great Barrier Reef. PLoS ONE 8:e68533

Valiere N (2002) GIMLET: a computer program for analyzing genetic individual identification data. Mol Ecol Notes 2:377-379

van Hooidonk R, Maynard JA, Manzello D, Planes S (2014) Opposite latitudinal gradients in projected ocean acidifi-

Editorial responsibility: Charles Birkeland, Honolulu, Hawaii, USA cation and bleaching impacts on coral reefs. Glob Change Biol 20:103-112

van Oosterhout C, Hutchinson W, Wills D, Shipley P (2004) MICRO-CHECKER: software for identifying and correcting genotyping errors in microsatellite data. Mol Ecol Notes 4:535-538

> van Oppen MJH, Gates RD (2006) Conservation genetics and the resilience of reef-building corals. Mol Ecol 15: 3863-3883

> Warner ME, LaJeunesse TC, Robison JD, Thur RM (2006) The ecological distribution and comparative photobiology of symbiotic dinoflagellates from reef corals in Belize: potential implications for coral bleaching. Limnol Oceanogr 51:1887-1897

Weil E, Knowlton N (1994) A multi-character analysis of the Caribbean coral Montastraea annularis (Ellis and Solander, 1786) and its two sibling species, M. faveolata (Ellis and Solander, 1786) and M. franksi (Gregory, 1895). Bull Mar Sci 55:151-175

> Woodley JD, Chornesky EA, Clifford PA, Jackson JBC and others (1981) Hurricane Allen's impact on Jamaican coral reefs. Science 214:749-755

Submitted: July 1, 2013; Accepted: March 28, 2014

Proofs received from author(s): May 28, 2014 